\title{
A COMPARATIVE STUDY OF THE TENSE AND ASPECT IN STANDARD KHASI AND ITS VARIETIES
}

\author{
Rymphang K. Rynjah
}

In this study, we will undertake a comparative study of the syntax of the Tense and Aspect of Standard Khasi, an Austro-Asiatic language spoken in the state of Meghalaya and its two varieties Trangblang and Mawlong. Trangblang belongs to the War-Jaintia dialect of Khasi and is spoken in Trangblang village situated in Amlarem Block in Jaiñtia Hills District. Mawlong, on the other hand, is a War-Khasi dialect of Khasi and is spoken in Mawlong village located in the East Khasi Hills District. The main aim of this study is to compare and contrast the similarity and variation between these varieties when compared with the Standard Khasi using a comparative methodology. This study also aims to present the morphology of Tense and Aspect and to account for the syntactic analyses of Tense and Aspect in these varieties.

Keywords: Austro-Asiatic, Standard Khasi, Tense and Aspect, comparative study.

\section{Introduction}

Khasi belongs to the Austro-Asiatic family of language and is spoken in the Central and Eastern part of the state of Meghalaya. Before 1813, Khasi had no script of its own. In the year 1813-14, translation of the Bible into the Khasi language was done using Bengali script because literacy was possible only in Bengali. Around 1816, a few more translated versions of the Gospel of Matthew were printed and distributed among some Khasis who could read the Bengali script. It was only with the coming of the Welsh missionary (1842) that the Roman script was introduced and translations were done in the standard dialect.

Khasi has significant dialectal variations; Grierson (1904) mentions of four dialects. These are Khasi proper, Pnar or the Synteng, the Lyngngam, and the War dialects. Khashi proper is the standard dialect used as the formal language and for all literary purposes. War dialects of Khasi are subdivided into two groups i.e. War-Khasi and War-Jaiñtia. They are spoken in the South-east corner of East Khasi Hills District and Jaiñtia Hills District respectively.

In Sidwell (2009), Daladier $(2007,341)$ remarks that the Mon Khmer group of languages has three main branches: The Khasi now standardized and fixed by written use, yet there are still unwritten dialects, particularly in the War region, the Pnar and War.

\section{Varieties under Study}

In this study, War-Jaiñtia is represented by Trangblang variety spoken in Trangblang village situated in Amlarem Block in Jaiñtia Hills district. It is located $25 \mathrm{~km}$ towards south from district headquarters Jowai and $46 \mathrm{~km}$ from the state capital Shillong. And on the other hand, WarKhasi is represented by Mawlong variety spoken in Mawlong village which is located in the East Khasi Hills district adjacent to Bangladesh and is about $65 \mathrm{~km}$ from the capital city Shillong.

\section{Aim of the study}

The present paper aims to compare and contrast the similarity and differences between the tense and aspect of the two varieties of War dialects i.e. Trangblang variety and Mawlong variety when compared with the standard Khasi.

\section{Tense and Aspect}

Tense as a grammatical concept has been defined as a grammatical expression of location in time (Comrie, 1985: 9). Therefore, tense specifies whether an action described and denoted by the verb is present, past or future. Lyons (1968: 305) 


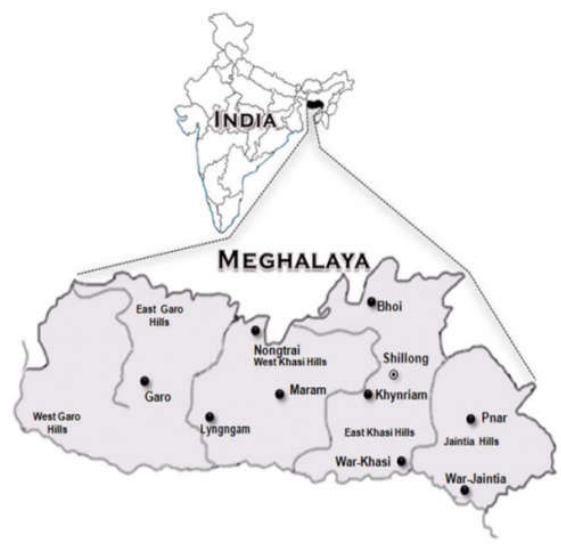

Figure 1: Map showing War Khasi and WarJaiñtia $^{1}$

explaining this category says that "[t]he essential characteristic of the category of the tense is that it relates the time of an action, event, or state of affairs referred to in the sentence to the time of utterance: the time of utterance begins now". According to Binnick (2012), the most influential syntactic definition of tense restricts the category to the morphemes that refer to present and past. The notion of aspect according to Comrie (1976:3) refers to "the different ways of viewing the internal temporal constituency of a situation".

A further crucial aspectual difference is that between perfective and imperfective aspects. Comrie characterizes these notions as follows.

"...perfectivity indicates the view of the situation as a single whole, without distinction of the various separate phases that make up the situation, while the imperfective pays essential attention to the internal structure of the situation." Comrie (1976:16).

4.1 The morphology of tense in standard Khasi and its varieties

There are three tense distinctions in Standard Khasi (SK), Mawlong variety (MV) and Trangblang variety (TV) as discussed below.

\subsubsection{Present tense}

In standard Khasi as well as in both the varieties Mawlong and Trangblang, the present tense is

${ }^{1}$ Map from Reddy et al. (2007) unmarked (ø). It is interesting to note that unlike in the standard Khasi in (1a) where the agreement marker $u$ 'third Singular Masculine' occurs before the verb, it is found that the agreement marker in the two varieties in (1b) and (1c) occurs after the verb go as shown in the following sentences below.
a. $\mathrm{u}$ ban $\mathrm{u} \quad \varnothing$ leyt skul (SK) 3SM Ban 3SM go school 'Ban goes to school'
b. u ban $\varnothing$ da skul u (MV) 3SM Ban go school 3SM 'Ban goes to school'
c. u ban $\varnothing$ le pure kot u (TV) 3SM Ban go read book 3SM 'Ban goes to school'

\subsubsection{Past tense}

In standard Khasi (SK), the past tense is indicated by the marker $l a$ and it occurs preverbally as shown in (2a) below. Mawlong variety also has the same marker la (2b), whereas, Trangblang variety has $d a$ as the past tense marker (2c). The placement of the past tense markers is consistent across all the varieties i.e. pre-verbal.

The only difference is in the placement of the agreement marker $u$ 'third singular masculine'. In SK, it is placed before the tense marker and in MV and TV $u$ is placed at the final position. We can also observe that the lexical item for 'buy' in MV and SK is different from TV.
a. $u$ hep $u$ la $\mathrm{t}^{\mathrm{h}}$ ied kot (SK) 3SM Hep 3SM PST buy book 'Hep bought a book'
b. $\mathrm{u}$ hep la $\mathrm{t}^{\mathrm{h}}$ ied kot $\mathrm{u}(\mathrm{MV})$ 3SM Hep PST buy book 3SM 'Hep bought a book'
c. u hep da kti kot u (TV) 3SM Hep PST buy book 3SM 'Hep bought a book'

\subsubsection{Future tense}

Following Nagaraja (1985), in standard Khasi the future marker is in and it has two forms (i) $-n$ after a vowel, which appears to be contracted from 
54 / A comparative study...

in and it is attached with the personal pronoun to indicate future tense as seen in (3a-b); and (ii) in after a consonant as shown in sentence (4a). The remote future $s a$ in standard Khasi can occur along with the future marker $-n$ which generally means to indicate work in the near future but without any specific or definite time as shown in (3c). The future marker of Trangblang variety is daw and there is no remote future marker in this variety as seen in sentence (3d-e). Mawlong variety (MV) does not show any definite overt future tense marker (3f). The remote future $s$ ? (in correspondence with the standard Khasi remote future $s a$ in (3c)) is used to refer to the future as seen in $(3 \mathrm{~g})$.

$$
\begin{aligned}
& \text { a. ka iba ka-n leyt minta (SK) } \\
& \text { 3SF Iba 3SF-FUT go school } \\
& \text { 'Iba will go now.' }
\end{aligned}
$$

b. u ban u-n leyt yew (SK) 3SM Ban 3SM-FUT go market 'Ban will go to the market.'
c. u ban u-n sa 3SM Ban 3SM-FUT REM.FUT
leyt yew (SK)
go market
'Ban will go to the market.'

d. ko iba daw le ko hynle (TV) $3 \mathrm{SF}$ Iba FUT go 3SF now 'Iba will go now.'
e. u ban daw le jai u (TV) 3SM Ban FUT go market 3SM 'Ban will go to the market.'
f. ka iba da ka mintan (MV) 3SF Iba go 3SF now 'Iba will go now.'
g. u ban so? da yu u (MV) 3SMBan REM.FUT go market 3SM 'Ban will go to the market'

The equivalent of the future tense maker $i n$ as seen in standard Khasi (4a) is absent in Mawlong variety (4b), whereas Trangblang variety uses $j u$ (4c).

(4) a. in ya leh kumno? (SK)
FUT ACC do what

'What will we do?'
b. ya leh kumno? (MV)
ACC do what
'What will we do?'
c. ki niah ju? leh? (TV)
NEU what FUT do
'What will we do?'

4.2 The morphology of aspects in standard Khasi and other varieties

In Standard Khasi, as well as in both Mawlong and Trangblang varieties, aspect is divided into perfective and imperfective as discussed below.

\subsubsection{Perfective aspect}

We understand that the action of the verb is completive as seen in the following sentences below where the marker of a completed action in standard Khasi and Mawlong variety is the item la? which precedes the main verb as seen in sentences (5-6) below, whereas, $d a$ in (7) is the perfective aspect marker in Trangblang variety.

Perfective aspect in the past tense

(5) a. u ban u la? dep bam ja (SK) 3SMBan 3SMPRF finish eat rice 'Ban had already eaten rice.'

b. ka iba ka lah dep wan na 3SF Iba 3SF PRF finish come $\mathrm{ABL}$ shnong (SK) village

'Iba had come from the village.'

(6) a. u ban la? dep sa jia u (MV) 3SM Ban PRF finish eat rice 3SM 'Ban had already eaten.'

b. ka iba lah wian ka nah 3SF Iba PRF come 3SF ABL shnong (MV) village 'Iba had come from the village.'

(7) a. u ban da dep ba ji u (TV) 3SM Ban PRF finish eat rice 3SM 'Ban had already eaten rice.'

b. ko iba da dep wan 
3SF Iba PRF finish come village

shnong ko (TV)

3SF

'Iba had come from the village.'

Perfective aspect in the present tense

(8) a. u ban u la? sho? jin-ieit (SK) 3SMBan 3SM PRF fall NOMZ-love 'Ban has fallen in love.'

b. ka iba ka lah bam (SK) 3SF Iba 3SF PRF eat 'Iba has eaten.'

(9) a. u ban la? shuo? jon-ied 3SM Ban PRF fall NOMZ-love u(MV)

3SM

'Ban has fallen in love.'

b. ka iba lah bam ka (MV) 3SF Iba PRF eat 3SF

'Iba has eaten'

(10) a. u ban da sho? maya u (TV) 3SM Ban PRF fall love 3SM

'Ban has fallen in love.'

b. ko iba da bam ko (TV)

3SF Iba PRF eat 3SF

'Iba has eaten.'

\subsubsection{Imperfective aspect}

(i) Durative

It talks about the span of the event and the utterance of the sentence. The durative marker $d a \eta$ in SK and TV in (11a) and (11b), and $d \supset y$ in MV in (11c) follows the main verb, though a distinction can be made from the standard Khasi with the varieties where the agreement marker $u$ occur postverbally in Mawlong and Trangblang varieties but preverbally in SK as seen in the following sentences below.
(11) a. u day pay (SK)
3SM IMPRF sick
'He's still sick.'

b. doy knied u(MV)
IMPRF sick
$3 \mathrm{SM}$
'He's still sick'
c. day chkow u(TV)
IMPRF sick 3SM
'He's still sick'

\section{(ii) Progressive}

It points to the progression of work. The Progressive nay in SK and MV in (12a) and (12b) and $d a$ in TV in (12c) occurs before the verb as seen in the following sentences below. We can also observe for the word ahead, MV uses 'hetkhmat', whereas, TV uses 'somat' which is different when compared to the SK which uses 'shakhmat'.

(12) a. ki nan iaid shakhmat (SK) 3PL IMPRF walk ahead 'They are walking ahead.'

b. ki nay iaid ki hetkhmat (MV) 3PL IMPRF walk 3PL ahead 'They are walking ahead.'

$$
\begin{aligned}
& \text { c. da kap ki somat (TV) } \\
& \text { IMPRF walk 3PL ahead } \\
& \text { 'They are walking ahead.' }
\end{aligned}
$$

(iii) Habitual

It points to the habituality, to the events that are true in the past and time of the utterance. Following sentences below illustrate the habitual markers which are seen to occur pre-verbally in standard Khasi (SK) as well as MV and TV.

$J u$ and fait in standard Khasi (SK)

(13) a. u ban u-m ju bam soh 3SM Ban 3SM-NEG IMPRF eat fruit 'Ban never eats fruits.'

b. ka lin ka fait bam ja 3SF Lin 3SF IMPRF eat rice shi'baje 1'clock 'Lin usually eats food at 1o'clock.' $j u ?$ and $\int i j$ in Mawlong variety (MV)
(14) a. u ban $\mathrm{m}-\mathrm{u}$ 3SM Ban NEG-3SM 
56 / A comparative study...

$\begin{array}{llll}\text { ju? } & \text { bam } & \text { soh } & \mathrm{u} \\ \text { IMPRF } & \text { eat } & \text { fruit } & \text { 3SM }\end{array}$

'Ban never eats fruits.'

b. ka lin $\quad$ ij $\quad$ sa jia

3SF Lin IMPRF eat rice

ka shi'baje

3SM 1'clock

'Lin usually eats food at 1o'clock.'

be? in Trangblang variety (TV)

be? is used to indicate 'most cases' as seen in the following sentences below.

(15) a. u ban aw be? ba soh u 3SM Ban NEG IMPRF eat fruit 3SM 'Ban never eats fruits.'

b. ko lin be? ba ji 3SF Lin IMPRF eat rice

ko shi'beje

3SF 1'clock

'Lin usually eats food at 1o'clock.'

(iv) Iterative marker

This point to the events happening many times as shown in the following sentences below. Comparing the iterative markers, it is observed $\mathrm{MV}$ in (16b) uses the same form yai as SK in (16a), whereas, this marker is absent in TV. The only difference is in the placement of the agreement marker $u$, in SK $u$ is placed before the iterative marker in (16a), whereas in MV, $u$ is placed at the final position as seen in sentence (16b) below. This marker is absent in Trangblang variety but instead manla $i$ por 'every time' is used.

(16) a. u

$\begin{array}{lllll}\text { u } & \text { ban } & \text { u } & \text { yai } & \text { leh } \\ \text { 3SM } & \text { Ban } & \text { 3SM } & \text { IMPRF } & \text { do } \\ \text { kam } & & \text { sniew } & \text { (SK) } & \\ \text { work } & & \text { bad } & & \end{array}$

'Ban continues to do bad work.'

b. u ban yai leh kam

3SM Ban IMPRF do work

snew u (MV)

bad 3SM

'Ban continues to do bad work.' c. u ban manla i por leh

3SM Ban every time do

kam kom u

work bad 3SM

(TV)

'Ban continues to do bad work.'

The Iterative marker can also occur along with the future tense in SK and remote future in MV as shown in sentences (17a) and (17b) below, whereas, in TV for the same sentence only the future marker daw is used.

$\begin{array}{lll}\text { ka iba } & \text { ka-n yai } \\ \text { 3SF Iba } & \text { 3SF-FUT } \\ \text { rwai beit } & \text { (SK) } \\ \text { IMPRF } & \text { sing } & \text { EMPHASIS } \\ \text { 'Iba will continue to sing (regardless of } \\ \text { anything).' }\end{array}$

b. ka iba

so?

3SF Iba

REM.FUT

yai rwia beit (MV)

IMPRF sing EMPHASIS

'Iba will continue to sing (regardless of anything)'
c. ka iba daw rway
3SF Iba FUT sing
bit ka (TV)
EMPHASIS $3 \mathrm{SF}$
'Iba will continue to sing (regardless of anything)'

\section{Conclusion}

This study basically shows that the morphemes used to indicate tense and aspect in Mawlong Variety (MV) and Trangblang Variety (TV) differ from those of standard Khasi (SK). This study has been able to highlight the morphology of tense, where the present tense is unmarked (ø)in both $\mathrm{MV}$ and TV similar to SK, the past tense is marked by $l a$ in the SK and MV but by $d a$ in TV. Future tense in SK is marked by $-n / i n$ and also has a remote future tense marker $s a$. MV does not exhibit any overt future tense marker but the remote future tense marker $s o$ ? is used among the native speakers when talking about or referring to the future. On the other hand, TV has daw and ju as future tense markers as shown in the following table 1 below. 
Table 1: A Comparative list of the Tense distinction of SK, MV and TV

\begin{tabular}{|l|l|l|l|}
\hline Tense & SK & MV & TV \\
\hline Present & $\phi$ & $\phi$ & $\phi$ \\
\hline Past & la & la & da \\
\hline Future & /-n/ and insa & $\phi$ & daw \\
& $\begin{array}{l}\text { (in remote } \\
\text { future) }\end{array}$ & $\begin{array}{l}\text { future /so?/ is } \\
\text { used }\end{array}$ & $j u$ \\
\hline
\end{tabular}

Two aspectual categories are examined in this paper: perfective and imperfective aspect.

The perfective aspect is marked by la? in SK and $\mathrm{MV}$, whereas $d a$ in TV.

The imperfective aspect markers only differ phonologically from that of standard Khasi, the durative is marked by $d a \eta$ in SK and TV and $d o \eta$ in MV, the progressive is marked by nay in SK and $\mathrm{MV}$, whereas in TV the progressive is marked by $d a$. Habitual aspect is marked by two markers in both SK and MV viz. ju and fait in SK and ju? and $\int i j$, whereas TV only has one habitual marker be?. Iterative aspect is marked by yai in both SK and MV and is absent in TV. The summary of aspect markers is shown in table 2 .

Table2: AComparative list of aspect markers in SK, MV and TV

\begin{tabular}{|l|l|l|l|}
\hline Aspect & SK & MV & TV \\
\hline Perfective & & & \\
\hline Imperfective & la? & la? & da \\
\hline Durative & dan & don & dan \\
\hline Progressive & nan & nan & da \\
\hline Habitual & ju and Jait & ju? and Sij & be? \\
\hline Iterativity & yai & yai & \\
\hline
\end{tabular}

6. References

Bareh, Mondon.1929. Khasi English Course and Grammar. Shillong: Ri Khasi Press.

Binnick, Robert I. 2012. The Oxford Handbook of Tense and Aspect. Oxford University Press.

Comrie, Bernard S. 1976. Aspect. Cambridge University Press.

Comrie, Bernard S. 1985. Tense. Cambridge University Press.
Daladier, Anne. 2002. Definiteness in Amwi: Grammaticalization and Syntax. In Recherches Linguistiques de Vincennes 31, edited by A. Z. Hert and A. Daladier: 61-78.

Daladier, Anne. 2007. Elements cosmogoniques et vocabulaire austroasiatique $d u$ groupe mônkhmer du Meghalaya. Interactions avec le monde indien, - Bulletin d'Études Indiennes: Paris: Collège de France.

Grierson, George A. 1904. Lingustic survey of India (Vol2,) Delhi: Motilal Banarsidass.

Hock, Hans H. 1991. Principles of Historical Linguistics. Second Edition. Berlin: Mouton de Gruyter.

Jyrwa, M. B. 1984. A contrastive study of tense and aspect in Khasi and English with reference to the teaching of English to Khasi speakers. An M. ED. Dissertation University of Manchester.

Liu, Yimin. 2014. A comparative study of English tense and French tense. English Department, Foreign Language College, Inner Mongolia University: China.

Lyons, John.1968. Introduction to theoretical linguistics. Cambridge: Cambridge University Press.

Nagaraja, K.S. 1985. Khasi: A descriptive analysis. Pune: Deccan College Postgraduate \& Research Institute.

Reddy, B. M., Langstieh, B. T., Kumar, V., Nagaraja, T., Reddy, A. N., Meka, A., Singh, L. (2007). Austro-Asiatic tribes of Northeast India provide hitherto missing genetic link between South and Southeast Asia. PloS one, 2(11), e1141. doi:10.1371/journal.pone.0001141

Sidwell, Paul. 2009. Classifying the Austroasiatic Languages: History and the state of the art. Muenchen: LINCOM Europa

Sten, H. W. 1987. Tense in Khasi Language. Khasi Studies 1(1). 